\title{
Eleições e Perfis: análise das assembleias legislativas da região Sul do Brasil (1998-2006)
}

\author{
Elections and Profiles: analysis of the legislative assemblies of Southern Brazil \\ (1998-2006)
}

\author{
Roberta Carnelos Resende \\ Universidade Federal do Paraná - Brasil \\ roberta_carnelos@yahoo.com.br \\ Rodrigo Cantu de Souza \\ Universidade do Estado do Rio de Janeiro - Brasil \\ gubrcr@hotmail.com
}

\section{Resumo}

O perfil dos políticos brasileiros tem sido abordado em um crescente número de estudos recentes (MARENCO DOS SANTOS, 1997; RODRIGUES, 2002; PERISSINOTO e BRAUNERT, 2006; PERISSINOTO et al., 2009). Os propósitos e as delimitações do objeto tem sido variadas: da classificação ideológica dos partidos, passando por mudanças nos perfil dos eleitos, ao exame dos valores políticos de parlamentares. Essa variedade de aplicações pode ser entendida como uma medida da importância heurística que o estudo do perfil dos políticos representa para a Ciência Política. O presente texto tem um duplo objetivo. O primeiro é examinar o perfil dos(as) candidatos(as) (socioeconômico, partidário e de gênero) aos legislativos estaduais nos três estados do sul do Brasil no período 1998-2006. A maior parte dos estudos que levanta o perfil de políticos investiga o perfil de parlamentares e este trabalho pretende, assim, contribuir com essa literatura. A elaboração dos perfis é feita, aqui, por meio de Análise de Correspondências Múltiplas (ACM), uma técnica estatística que distribui indivíduos em dimensões relevantes para a observação de suas diferenças. Dessa maneira, o segundo objetivo é contribuir metodologicamente, testando as possibilidades dessa técnica como um modo mais sofisticado para elaborar o perfil de políticos.

Palavras-Chave: Eleições; Perfil de candidatos/as; ACM.

\begin{abstract}
The profile of Brazilian politicians have been addressed in a growing number of recent studies (MARENCO DOS SANTOS, 1997; RODRIGUES, 2002; PERISSINOTO e BRAUNERT, 2006; PERISSINOTO et al., 2009). The purposes and object delimitations have been varied: from the ideological classification of the parties, passing by the changes in the profile of the elects, to the examination of the parliamentary political values. This variety of applications can be understood as a heuristic measure of the importance that the study of the profile of politicians has to Political Science. This paper has, thus, a double aim. The first is to examine the profile of (the) candidate(s) (socioeconomic, and related to party and gender) to the state legislative power in the three Southern states of Brazil in 1998-2006. Most studies that raises the profile of politicians investigate members of Congress and this work, thus, aims to contribute to this literature. The preparation of the profiles is made here by means of a Multiple Correspondence Analysis (MCA), a statistical technique that distributes individuals in relevant dimensions to observe their differences. Thus, the second objective is to give a methodological contribution, testing the possibilities of this technique as a more sophisticated way to elaborate politicians profiles.
\end{abstract}

Keywords: Election; Candidate profile; ACM. 


\section{Introdução}

O perfil dos políticos brasileiros tem sido abordado em um crescente número de estudos recentes (MARENCO DOS SANTOS, 1997; RODRIGUES, 2002; PERISSINOTO e BRAUNERT, 2006; PERISSINOTO et al., 2009). Os propósitos e as delimitações do objeto têm sido variados: da classificação ideológica dos partidos, passando por mudanças nos perfil dos eleitos, ao exame dos valores políticos de parlamentares. Essa variedade de aplicações pode ser entendida como uma medida da importância heurística que o estudo do perfil dos políticos representa para a Ciência Política. O presente texto tem um duplo objetivo. O primeiro é examinar o perfil dos candidatos (socioeconômico, partidário e de gênero) aos legislativos estaduais nos três Estados do sul do Brasil no período 1998-2006. A maior parte dos estudos que levanta o perfil de políticos investiga o perfil de parlamentares e este trabalho pretende, assim, contribuir com essa literatura. A elaboração dos perfis é feita, aqui, por meio de Análise de Correspondências Múltiplas (ACM), uma técnica estatística que distribui indivíduos em dimensões relevantes para a observação de suas diferenças. Dessa maneira, o segundo objetivo é contribuir metodologicamente, testando as possibilidades dessa técnica como um modo mais sofisticado para elaborar o perfil de políticos. Em uma primeira seção são esclarecidos os dados utilizados e a metodologia empregada. Em uma segunda seção, são apresentados os resultados das análises. Concluímos com breves considerações finais.

\section{Dados e Metodologia}

O objetivo desse texto é explorar os diferentes perfis dos candidatos a deputado estatual no Paraná, em Santa Catarina e no
Rio Grande do Sul. Um procedimento bastante comum quando se faz investigação de perfis em Ciência Política é a utilização de tabelas cruzadas. Esse procedimento permite observar como se relacionam duas variáveis (partido e ocupação, por exemplo) e, assim, é possível observar se há algum tipo de associação mais forte entre determinadas categorias dessas variáveis. O problema com as tabelas cruzadas é que elas não permitem a observação da associação entre diversas variáveis simultaneamente. Desse modo, há uma limitação, pois só se pode examinar a relação entre duas variáveis de cada vez. É possível analisar como determinada ocupação ou escolaridade se relaciona com determinado partido, como determinado gênero se relaciona com determinada performance eleitoral, etc. Entretanto, não é possível examinar as relações entre todas essas variáveis juntas. É exatamente isso que a Análise de Correspondências Múltiplas permite, na medida em que essa técnica constrói eixos nos quais os indivíduos se encontram mais distante uns dos outros conforme a dissemelhança de seus perfis, ou seja, conforme o número de propriedades que eles não possuem em comum. Esse método é descrito com mais profundidade em seguida.

A amostra de indivíduos recolhidos para a análise consiste em cada candidatura para deputado estadual no três Estados do sul nas eleições de 1998, 2002 e de 2006. Cada observação corresponde, dessa maneira, a cada candidatura. Um mesmo indivíduo que se candidatou nessas três eleições, aparece três vezes no banco de dados. A razão disso é que certas propriedades relevantes dos indivíduos variam de eleição a eleição como, por exemplo, o fato de o candidato ter sido eleito. $\mathrm{Na}$ eleição seguinte, isso se constitui enquanto uma característica bastante distintiva, como será visto em seguida. Para cada candidatura, foram compostas 13 variáveis, as quais estão descritas em detalhes 
no Quadro 1. Os dados foram fornecidos pelo Tribunal Superior Eleitoral.

Para explorar as associações entre as variáveis estudadas e construir um espaço no qual se constituem diferentes perfis de candidatos, utilizamos, como já mencionado, a Análise de Correspondências Múltiplas (ACM). A ACM é uma abordagem formalgeométrica da estatística multivariada, surgida nos anos sessenta na França em torno do matemático Jean-Paul Benzécri. Ela se constitui a partir da generalização dos princípios da Análise de Correspondências, que é um método aplicado no estudo de tabelas de contingência, a tabelas indivíduosvariáveis. A partir dos anos setenta, estes métodos geométricos conheceram um sucesso representativo na França em um grande número de disciplinas, mas eles permanecem muito pouco reconhecidos no Brasil ${ }^{1}$. Os princípios desse tipo de análise são: 1) a modelização geométrica, onde os dados são representados como nuvens de pontos em espaços euclidianos, em oposição à pesquisa de sumários quantitativos; 2) a abordagem formal baseada na álgebra linear abstrata, ao invés do cálculo matricial; e 3) o procedimento indutivo, no qual a descrição vem primeiro (ao contrário dos modelos estocásticos, que são estabelecidos no começo) e a indução estatística é concebida como um prolongamento das conclusões descritivas (ROUANET, 2005).

A seguir estão listadas as 13 variáveis elaboradas para a utilização na Análise de Correspondências Múltiplas (ACM). Ao lado do nome da variável, há, primeiro, seu número de modalidades, segundo, a descrição das modalidades. Sobre os dados e sobre a composição das variáveis, são necessárias algumas observações. Cada observação corresponde a cada candidatura; portanto, se um indivíduo se candidata em mais de uma eleição, seu nome aparece mais de uma vez na listagem. Quanto ao partido ao qual os candidatos são filiados, foram formuladas quatro variáveis para captar uma divisão entre grandes e pequenos partidos. Para todas as observações e, posteriormente, em separado para cada eleição, foram codificados os partidos com mais de 5\% de candidatos. Os demais partidos, menores, com mais de 5\% de candidatos foram colocados na categoria "outros". Nas ACMs, se utilizou sempre a codificação correspondente ao ano em questão. A variável ocupação foi elaborada segundo as categorias presentes em Rodrigues (2002). O total de observações é 3626. O número de observações para cada eleição é o seguinte: para 1998, 1112; para 2002, 1205; para 2006, 1309. As análises foram rodadas no programa SPSS. Os sumários estatísticos dos resultados dos modelos encontram-se no apêndice. Com o intuito de facilitar a argumentação sobre as diferentes ACMs é utilizada a seguinte notação. Para a ACM que abrange todas as eleições: $\mathrm{ACM}_{\text {total }}$. Para a ACM abrangendo a eleição de 1998: $\mathrm{ACM}_{1998}$. Para a ACM abrangendo a eleição de 2002: $\mathrm{ACM}_{2002}$. Para a ACM abrangendo a eleição de 2006: $\mathrm{ACM}_{2006}$.

Esse método geométrico, a ACM, permite construir um espaço estruturado de diferenças, definindo distâncias entre indivíduos com atributos distintos e aproximando indivíduos com atributos semelhantes. Cada atributo é colocado na análise como uma variável. Para cada variável, pode-se pensar em uma representação espacial e, para um conjunto de n variáveis, pode-se estabelecer uma representação de uma 'nuvem' de pontos em n + 1 dimensões. O objetivo da ACM é proporcionar uma visão tangível de realidades multidimensionais por meio da redução das dimensões. Isso é feito através da representação das modalidades e indivíduos em eixos onde as variâncias dos dados são maximizadas, chamados eixos de inércia ou 
Quadro 1.

Ano da eleição (3) - 1998; 2002; 2006.

Estado (3) - Paraná, Rio Grande do Sul; Santa Catarina.

Partido:

Todos os anos (10): - PDT; PFL; PMDB; PPB; PPS; PSB; PSDB; PT; PTB; Outros

1998 (8) - PDT; PFL; PMDB; PPB; PSDB, PT PTB; Outros

2002 (11) - PDT; PFL; PL; PMDB; PPB; PPS; PSB; PSDB; PT; PTB; Outros.

2006 (10) - PDT; PMDB; PP; PPS; PSB; PSDB; PT; PTB; PV; Outros.

Situação (2) - Eleito; Nāo eleito.

Gênero (2) - Homem; Mulher.

Em Mandato (2) - Em mandato; Nāo em mandato.

Ocupação (10) - Político; Empresário; Profissōes liberais e intelectuais; Professores; Comunicadores/Padres/Pastores; Empregados nāo manuais em serviços; Trabalhadores industriais e lavradores; Administraçāo pública; Outros.

Idade (5) - Menos de 30 anos; entre 31 e 40; entre 41 e 50; entre 51 e 60; 61 ou mais.

Estado Civil (3) - Casado; Solteiro; Viúvo/Divorciado.

Escolaridade (3) - Até ensino médio incompleto; Até superior incompleto; Superior completo.

eixos fatoriais. Em outras palavras, uma vez que o espaço é definido pela escolha das variáveis ativas, a análise geométrica dos dados consiste em reduzir o número de dimensões desse espaço criando um novo sistema de eixos, esse novo sistema de eixos sendo aquele no qual a variância da nuvem projetada sobre a primeira dimensão seja máxima (ou seja, na qual, sobre esse eixo, a variância da nuvem seja a mais elevada possível) e assim por diante para cada dimensão seguinte (BENZÉCRI, 1992; ESCOFIER e PAGÈS, 1992; LEBARON, 2006).

Os resultados básicos da ACM incluem os seguintes elementos: a representação geométrica dos indivíduos e das modalidades; o autovalor associado a cada eixo, que indica a variância da nuvem de pontos no eixo; e, por fim, as contribuições de cada variável para a formação de cada eixo. $\mathrm{O}$ procedimento de interpretação estatística começa com a observação da variância dos eixos com o intuito de estabelecer quantos eixos serão utilizados. Normalmente não são utilizados mais que três ou quatro eixos. Em segundo lugar, estudam-se as contribuições relativas das variáveis para a formação dos eixos através de seus índices de discriminação. Esses índices são porções da variância total de um determinado eixo, sendo que a soma do índice de discriminação de todas as variáveis em um eixo é igual ao autovalor do eixo. Assim, interpreta-se o eixo em um sentido concreto, pois as variáveis que mais discriminam em um eixo são 
aquelas que organizam as maiores oposições em uma determinada dimensão deste espaço social analiticamente construído. (BENZÉCRI, 1992; LEBARON, 2006). Assim, quando falamos em explorar os diferentes perfis dos candidatos, estaremos analisando o significado dos eixos a partir das variáveis que contribuem para sua formação, ou seja, estaremos interpretando os eixos fatoriais como dimensões (onde existem oposições entre determinadas categorias) segundo os quais o espaço se organiza. A partir disso, é possível identificar diferentes posições nesse espaço, as quais correspondem a diferentes perfis.

\section{Resultados}

Dentre os resultados da ACM serão utilizados apenas o primeiro e o segundo eixos fatorais ${ }^{2}$. $\mathrm{O}$ primeiro passo para a interpretação desses dois eixos consiste em observar as contribuições das variáveis para a formação de cada um. Essa informação encontra-se na Tabela 1, a qual mostra as variáveis que mais contribuem para a formação de cada eixo em cada um dos modelos. Para os modelos com todas as observações, com as candidaturas em 1998 e com as candidaturas em 2006, as mesmas variáveis são as principais para a formação dos eixos. Para o primeiro eixo, as mais importantes são 'Em mandato', 'Situação', 'Ocupação', 'Partido'; para o segundo eixo, as mais importantes são 'Ocupação' e 'Escolaridade'. No modelo para as candidaturas em 2002, algumas outras variáveis aparecem em meio às mais importantes: no primeiro eixo, há ainda 'Escolaridade'; no segundo, aparecem também 'Partido', 'Em mandato' e 'Situação'. A ordem descendente das variáveis com maiores índices de discriminação (que mais discriminam os indivíduos em um eixo e, portanto, que mais contribuem para sua formação) também aparece alterada. De todo modo, o modelo para a eleição de 2002 pode, apesar disso, compartilhar da interpretação elaborada para os outros modelos. A diferença está somente em que a interpretação das dimensões segundo as quais os indivíduos se opõem não possui a mesma clareza e precisão para o ano de 2002.

Tabela 1 - Variáveis com maiores índices de discriminação em cada eixo.

\begin{tabular}{|c|c|c|}
\hline \multirow{2}{*}{ ACM } & \multicolumn{2}{|c|}{ Variáveis que mais contribuem para a formaçāo do eixo* } \\
\hline & Eixo 1 & Eixo 2 \\
\hline \multirow{3}{*}{ total } & Em mandato $(0,507)$ & Ocupaçāo $(0,672)$ \\
\hline & Situaçāo $(0,481)$ & Escolaridade $(0,533)$ \\
\hline & Ocupaçāo $(0,435)$ & \\
\hline $\mathrm{n}=3626$ & Partido $(0,287)$ & \\
\hline \multirow{3}{*}{1998} & Em mandato $(0,604)$ & Ocupaçāo $(0,701)$ \\
\hline & Situaçāo $(0,554)$ & Escolaridade $(0,598)$ \\
\hline & Ocupaçāo $(0,454)$ & \\
\hline $\mathrm{n}=1112$ & Partido $(0,290)$ & \\
\hline \multirow{4}{*}{2002} & Ocupaçāo $(0,424)$ & Ocupaçāo $(0,576)$ \\
\hline & Em mandato $(0,399)$ & Escolaridade $(0,395)$ \\
\hline & Escolaridade $(0,344)$ & Partido $(0,207)$ \\
\hline & Partido $(0,344)$ & Em mandato $(0,192)$ \\
\hline \multirow[t]{2}{*}{$n=1205$} & Situaçāo $(0,333)$ & Situaçāo $(0,18)$ \\
\hline & Em mandato $(0,553)$ & Ocupaçāo $(0,673)$ \\
\hline \multirow[t]{2}{*}{2006} & Situaçāo $(0,523)$ & Escolaridade $(0,558)$ \\
\hline & Ocupaçāo $(0,519)$ & \\
\hline$n=1309$ & Partido $(0,284)$ & \\
\hline
\end{tabular}

\section{Roberta Carnelos Resende e Rodrigo Cantu de Souza}


gráfico (não é importante se elas se encontram juntas do lado direito ou esquerdo arbitrariamente composta pelo programa do gráfico, pois a direção do eixo é

Gráfico 1 - Modalidades no plano com o primeiro e o segundo eixos fatoriais. Todas as candidaturas 1998-2006.

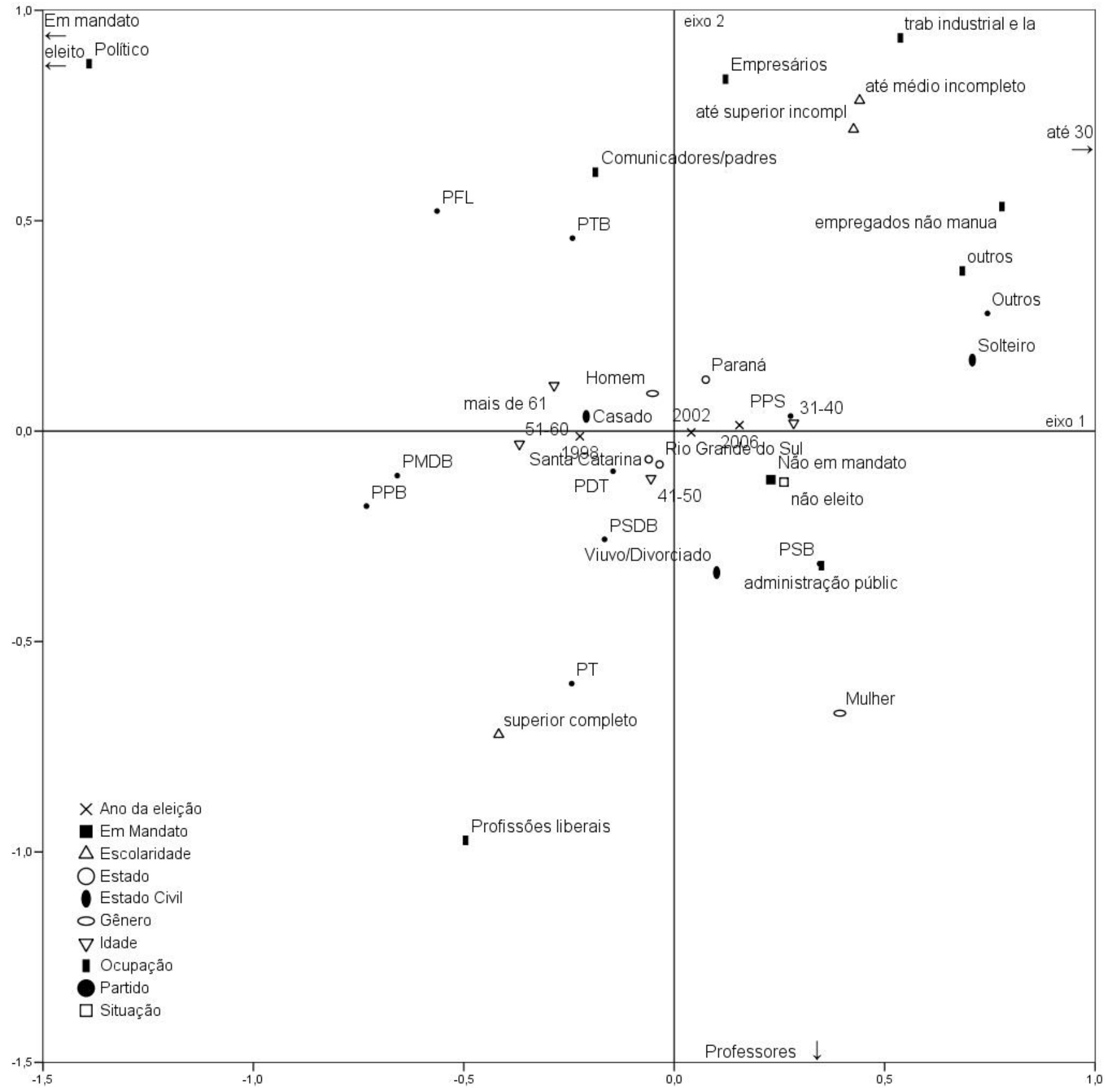


Eleições e Perfis: análise das assembleias legislativas da

região Sul do Brasil (1998-2006)

Gráfico 2 - Modalidades no plano com o primeiro e o segundo eixos fatoriais. Candidaturas de 1998.

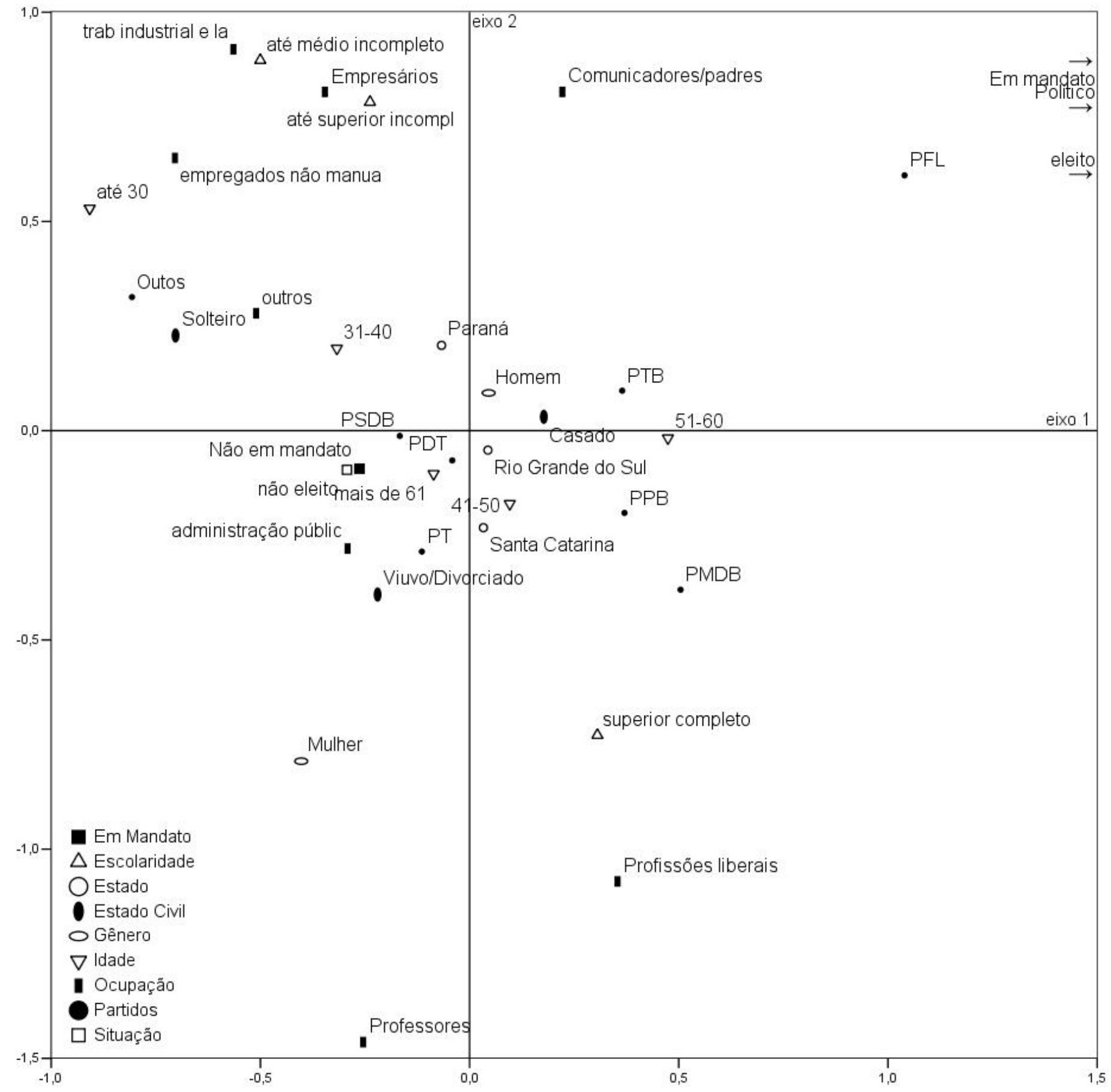

Roberta Carnelos Resende e Rodrigo Cantu de Souza 
Eleições e Perfis: análise das assembleias legislativas da

região Sul do Brasil (1998-2006)

Gráfico 3 - Modalidades no plano com o primeiro e o segundo eixos fatoriais. Candidaturas de 2002.

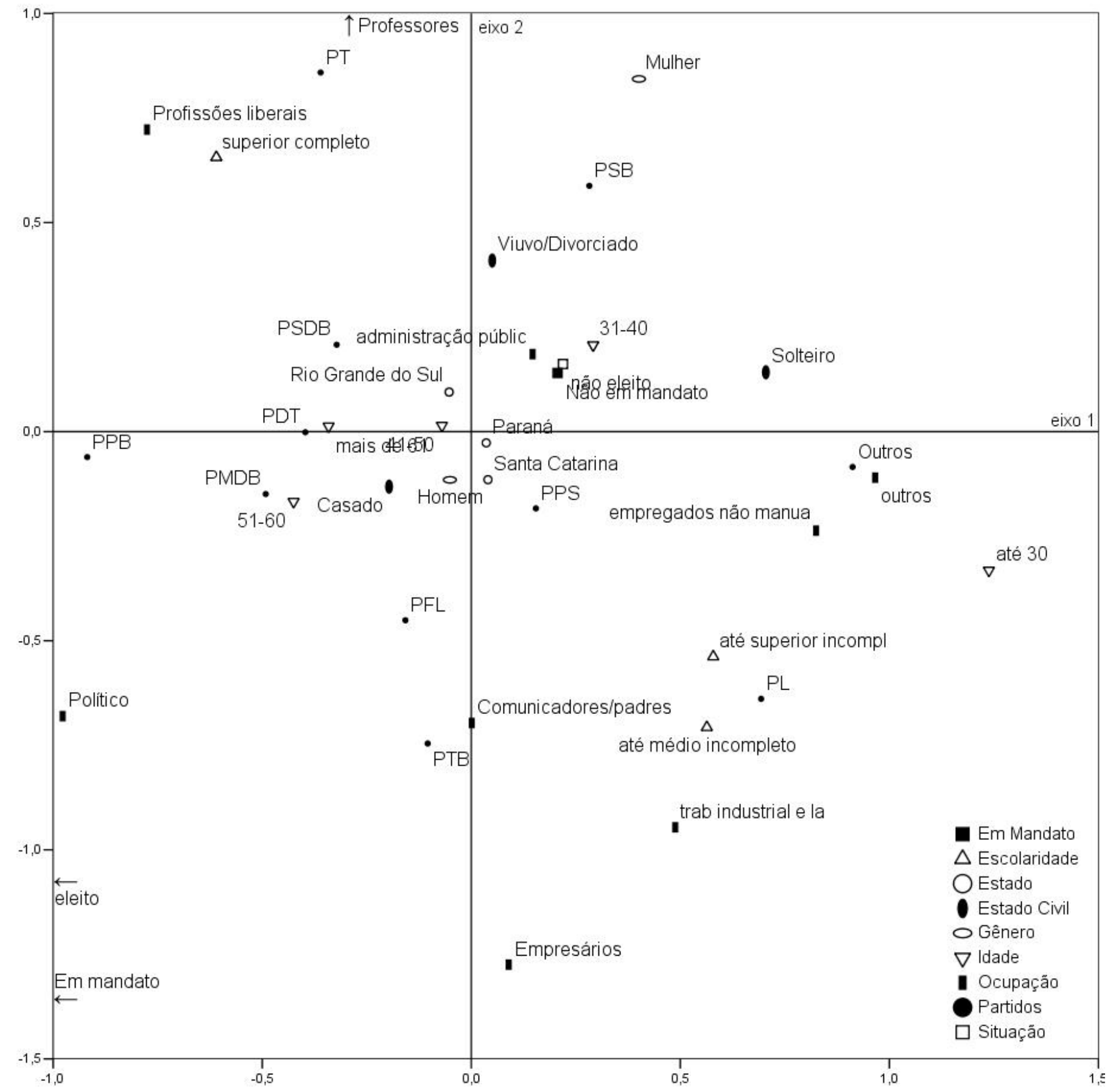

Roberta Carnelos Resende e Rodrigo Cantu de Souza 
Gráfico 4 - Modalidades no plano com o primeiro e o segundo eixos fatoriais. Candidaturas de 2006.

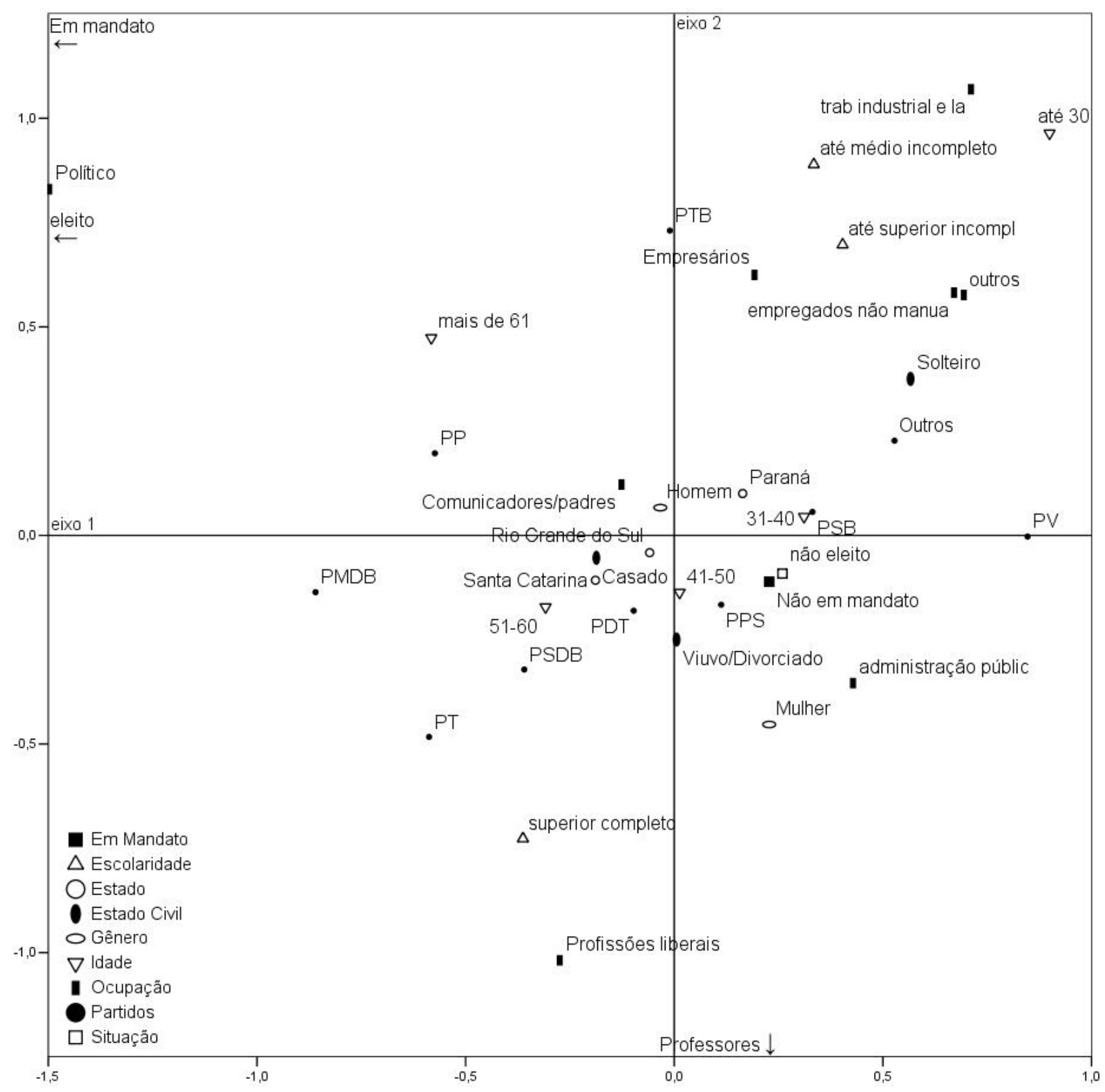

A direção dos eixos pode, assim ser invertida sem que os resultados sofram qualquer alteração). Do lado oposto do gráfico, encontram-se as modalidades que correspondem a indivíduos que não tiveram mandato como deputado estadual na eleição anterior e que não foram eleitos na eleição em questão. Em seguida, se observar a distribuição das modalidades para as variáveis 'Ocupação' e 'Partido', é possível reconhecer as seguintes oposições. De um lado, correspondendo às características de eleito e em mandato, encontra-se a modalidade de ocupação 'Político', assim como encontram-se também os partidos que mais elegeram pessoas em relação ao número 
total de seus candidatos. De outro lado, encontram-se as modalidades para as outras ocupações, assim como os partidos menores e aqueles que elegeram menos pessoas em relação ao número total de seus candidatos. Dadas essas oposições, é possivel interpretar esse primeiro eixo como um eixo de performance eleitoral. Ao longo dele, os candidatos se dividem entre aqueles com sucesso eleitoral e aqueles que não conseguiram uma vaga nas Assembleias Legislativas. O polo do primeiro eixo que corresponde ao sucesso eleitoral é, em todos os modelos, aquele no qual se encontra a modalidade 'eleito', evidentemente. Mas, além dela, também a modalidade 'Político' para a ocupação e, ainda, a modalidade 'Em mandato'. Esse resultado é mais uma evidência de que as Assembleias Legislativas dos Estados do sul são lugares de políticos profissionais, ambiente no qual a abertura para novos entrantes é sempre menor do que a manutenção de deputados em seus cargos.

Para a interpretação do segundo eixo, é observada a distribuição nos Gráficos 1, 2, 3 e 4 das modalidades das variáveis 'Ocupação' e 'Escolaridade'. Em todos os modelos, são encontradas as seguintes oposições. De um lado, encontram-se as modalidades que correspondem a indivíduos que possuem até o ensino médio incompleto e que correspondem a indivíduos possuindo até o superior incompleto. Junto a essas modalidades, encontram-se também as categorias ocupacionais dos empresários, dos trabalhadores industriais e lavradores, dos empregados não manuais em serviços e de outras ocupações. É desse lado, também, que se encontra a modalidade dos políticos profissionais. De outro lado, está a modalidade que corresponde a pessoas que concluíram o ensino superior, junto às categorias ocupacionais de professores, profissões liberais e intelectuais e, ainda, administração pública. Essas oposições permitem a seguinte interpretação: o segundo eixo é uma dimensão na qual se distinguem candidatos de estratos sócio-ocupacionais intensivos em recursos culturais pessoais $e$ estratos não tão intensivos nesses recursos. Além disso, essa oposição corresponde ainda aproximadamente à conclusão chegada por Bourdieu (1979), segundo a qual os estratos dominantes da sociedade dividem-se entre, de um lado, um polo dono de poderes econômicos e políticos e, de outro lado, um dono de poderes técnicos e culturais. É possível adaptar essa perspectiva e adequá-la a interpretação do segundo eixo fatorial, afirmando que, aqui, os candidatos dividemse entre, de um lado, aqueles donos de poderes técnicos, culturais e burocráticos (profissionais liberais e intelectuais, professores, administração pública) e, de outro lado, aqueles donos de poderes econômicos (empresários) e políticos (políticos profissionais) ou aqueles subordinados a estes (trabalhadores não manuais em serviços e trabalhadores industriais e lavradores).

Uma vez que o primeiro eixo foi interpretado como uma dimensão de desempenho eleitoral e o segundo como uma dimensão que opõe estratos sócioocupacionais intensivos em recursos culturais e estratos que não o são, pode-se passar ao exame da distribuição das modalidades das outras variáveis nos gráficos. Dessa maneira, é possível relacionar conjuntos de propriedades em posições específicas dos gráficos e, assim, estabelecer diferentes perfis dos candidatos.

\section{Diferença entre as Eleições e Diferença entre os Estados}

Ao colocar como uma variável o Estado da candidatura, é possível observar se algum Estado possui candidatos mais associados a um determinado perfil. Os resultados 
indicam, entretanto, que pouco importa o Estado: o conjunto dos candidatos possuem perfis diferenciais semelhantes em todo sul. Em todos os modelos as contribuições da variável 'Estado' foram muito pequenas. Isso pode ser identificado nos gráficos, pois as modalidades do Paraná, de Santa Catarina e do Rio Grande do Sul encontram-se sempre muito próximas do centro do gráfico. Essa distribuição das modalidades e seus baixos índices de discriminação demonstram que as diferenças explicitadas nos eixos da Análise de Correspondência se adequam ao conjunto dos candidatos dos três Estados, sem que algum deles tenha mais correspondência com algum perfil específico.

Quando às diferenças entre as eleições, é possível afirmar que, no geral, a estrutura de diferenças entre os candidatos se manteve relativamente constante. A razão disso é que a mesma interpretação para os eixos da ACM se adequou a todos os modelos. Em cada eleição, há modificações quanto ao posicionamento dos partidos, dado seus relativos sucessos eleitorais e dada a composição sócio-ocupacional do conjunto de seus candidatos. Todavia, a estrutura geral de oposições entre as categorias das variáveis permaneceu bastante semelhante em todos os modelos.

\section{Faixas Etárias e Estado Civil}

Em todos os modelos, a variável 'Idade' tem uma importância reduzida para a formação dos eixos. Entretanto, a distribuição das modalidades dessa variável dá, ainda assim, uma informação interessante sobre as diferenças etárias correspondentes a cada perfil. Em primeiro lugar, as medidas de discriminação dessa variável são sempre maiores no primeiro que no segundo eixo. Esse resultado é também identificável quando se observa os gráficos. Em todos os modelos, as modalidades dessa variável se distribuem mais ao longo do primeiro eixo que ao longo do segundo. Quase todas as modalidades encontram-se próximas do centro dos gráficos (31-40, 41-50, 51-60 e mais de 60). Isso indica que as propriedades que realmente criam distâncias entre os indivíduos nos modelos (performance eleitoral e estrato sócio-ocupacional) podem estar presentes em candidatos de qualquer uma dessas faixas etárias próximas ao centro dos gráficos, não havendo alguma associação especial entre idade e determinado perfil. A exceção é a modalidade atribuída a candidatos com até 30 anos. Nos quatro modelos, ela se localiza, considerando o primeiro eixo, do lado que representa o perfil de desempenho eleitoral sem sucesso. Assim, é possível notar como o insucesso eleitoral nas candidaturas a deputado estadual, no sul, estão associadas a essa faixa etária mais jovem. Uma hipótese para tal resultado pode ser a própria posição do cargo no cursus honorum brasileiro (MIGUEL, 2003). A eleição para deputado estadual já exigiria uma quantidade mediana de recursos políticos que as geração mais jovens que ainda não tiveram tempo de conquistar. Se observarmos, ainda, a modalidade dos candidatos com até 30 anos quanto a sua posição no segundo eixo, é possível identificá-la numa posição que está sempre mais ligada ao polo sócioocupacional não intensivo em capital cultural que as outras faixas etárias. Isso se deve a sua associação com a modalidade ocupacional 'outros', a qual é em grande parte é formada por estudantes, característicos dessa faixa etária mais jovem.

\section{Partidos e Ocupações}

Quando a Ciência Política toma como tarefa a elaboração de classificações de partidos, essas classificações remetem comumente, mesmo que segundo diferentes métodos, a suas diferenças ideológicas 
(KINZo, 1993; FIGUEIREDO e LIMONGI, 1999; MAINWARRING et al., 2000; LEONI, 2002; RODRIGUES, 2002; ZUCCO, 2009). Os resultados do presente estudo possibilitam menos qualquer inferência que possa levar a tal tipo de classificação que comentários sobre a localização dos partidos segundo performance eleitoral e composição sócioocupacional (no sentido da segunda dimensão das ACMs). Dessa maneira, os resultados quanto aos partidos serão debatidos de modo semelhante a Rodrigues (2002), mesmo que, aqui, a relação entre partidos e sua posição numa dimensão sócio-ocupacional revele aspectos meramente sugestivos sobre as ideologias partidárias.

No modelo elaborado com as candidaturas da eleição de 1998, os partidos se distribuem da seguinte forma ao longo do primeiro eixo: no lado direito do Gráfico 2, estão PFL, PTB, PPB e PMDB; no centro, estão PT, PDT e PSDB; no lado esquerdo, está a modalidade referente a outros partidos. Correspondendo à interpretação do primeiro eixo fatorial esboçada anteriormente, nessa primeira dimensão, os partidos se diferenciam segundo seu sucesso eleitoral. Os quatro partidos que se encontram no lado direito do gráfico são aqueles com o maior sucesso relativo. Esses partidos lograram eleger, cada um, em torno de $20 \%$ de seus candidatos. A exceção, nesse grupo, é o PFL, que logrou eleger $31,5 \%$ de seus candidatos. Quanto aos três partidos localizados no centro do gráfico, trata-se de partidos de médio sucesso eleitoral. Nessa eleição, PT, PDT e PSDB elegeram, respectivamente, $15,3 \%, 10,8 \%$ e $8,5 \%$ de seus candidatos. $\mathrm{O}$ restante dos partidos, representados na categoria "outros", no lado esquerdo do gráfico, são aqueles de sucesso eleitoral baixíssimo. Nas eleições de 1998, somente um candidato se elegeu de todos os partidos agrupados nessa categoria.

A mesma lógica divide os partidos ao longo do primeiro eixo nos modelos com dados de cada uma das outras eleições e no modelo com os dados agrupados das três eleições. No modelo para o ano de 2002, é possível identificar, no lado esquerdo do Gráfico 3, um grupo de alto sucesso eleitoral, incluindo PPB, PMDB, PDT, PT, PSDB, PFL; também é possível identificar um grupo de médio sucesso eleitoral, PTB e PPS; e ainda há um grupo de baixo sucesso nas eleições que conta com o PL e o restante dos partidos. No modelo para a eleição de 2006 (Gráfico 4), temos os seguintes resultados. Alto sucesso eleitoral: PMDB, PP e PT; médio sucesso eleitoral: PSDB, PDT, PTB e PPS; baixo sucesso: PSB, PV e demais partidos. No modelo que abrange todas as candidaturas no período estudado, observa-se a seguinte configuração. Alto sucesso eleitoral: PPB, PMDB, PFL, PT e PTB; médio sucesso eleitoral: PDT e PSDB ; baixo sucesso: PPS, PSB e o restante dos partidos. Em suma, há variações nas posições dos partidos na dimensão de sucesso eleitoral, o que corresponde também a quantidade de eleitos em relação ao número de candidaturas do partido, de ano a ano. Entretanto, vale mencionar, por um lado, os casos do PMDB e do $\mathrm{PPB} / \mathrm{PP}^{3}$, o qual sempre está incluído no grupo de alto sucesso. Por outro lado, os partidos pequenos sempre se encontram no polo de baixo sucesso eleitoral.

A distribuição dos partidos ao longo do segundo eixo é realizada com a observação do modelo para o conjunto de todas as candidaturas de 1998 a 2006. No gráfico 1, é possível observar como essa dimensão separa os candidatos de acordo com um perfil sócioocupacional mais intensivo em capital cultural (professores, profissões liberais e intelectuais, administração pública), na parte inferior, dos candidatos com um perfil não tão intensivo nesse tipo de recurso (empresários, políticos, trabalhadores industriais e lavradores, empregados não manuais em serviços), na parte superior. 
Nesse modelo, a oposição mais clara é entre o PT, na parte inferior, e o PFL e o PTB na parte superior. Oposição semelhante, apenas com pequenas variações, é encontrada nos modelos para cada eleição específica. Esse resultado é interessante, pois é quase consensual na literatura a classificação ideológica do PT como partido de esquerda e a do PFL e do PTB como partidos de direita para estudos que tomam a Câmara dos Deputados como objeto. O modelo aqui elaborado permitiu captar essa oposição por meio de uma dimensão sócio-ocupacional para os legislativos estaduais do sul do país. Assim, em primeiro lugar, é possível identificar uma correspondência entre ideologia partidária e a composição sócioocupacional de seus candidatos e, em segundo lugar, é possível notar a congruência entre os resultados da literatura para o plano nacional e para o plano estadual/regional no caso do sul.

Utilizando a bancada de cada partido na Câmara dos Deputados, Rodrigues (2002) chega a conclusões semelhantes quanto a oposição entre PT, de um lado e PFL e PTB, de outro. O presente estudo, tendo um objeto distinto do de Rodrigues, isto é, todas as candidaturas para os legislativos estaduais do sul, chega a resultados ligeiramente diferentes. Em Rodrigues (2002), um dos principais fatores para a classificação do PT como partido de esquerda é a grande proporção de trabalhadores industriais e empregados não manuais em serviços. Para a amostra que constitui o objeto do presente estudo, essas categorias ocupacionais não foram as mais relevantes para a determinação da oposição entre os partidos. Dentre todos os candidatos do PT, no período em questão, $6,8 \%$ eram trabalhadores industriais ou lavradores. O PTB, por sua vez, possui $6,7 \%$ de seus candidatos nessa mesma categoria ocupacional. Como visto na interpretação do segundo eixo, trata-se de uma dimensão que opõe estratos sócio-ocupacionais intensivos em recursos culturais de outros estratos, nomeadamente, aqueles detentores de poderes econômicos e políticos ou aqueles subordinados a esses poderes. Dessa maneira, segundo os resultados do modelo aqui elaborado, essa é a oposição relevante entre a composição dos partidos no sul.

\section{Gênero}

A participação feminina nos legislativos e na política brasileira em geral se tornou, já há alguns anos, um importante tema de discussão (AVELAR, 2001; ARAÚJO, 2005; MIGUEL e BIROLI, 2009). Nos dados que tomamos como objeto, as mulheres aparecem em uma quantidade bem menor em relação aos homens. Apenas 11,7\% das candidaturas do período estudado são de mulheres. De todo modo, passamos agora ao exame da variável gênero. Em todos os modelos aqui elaborados, a modalidade correspondente a candidatos do sexo masculino encontra-se sempre próxima ao centro do gráfico. O significado desse posicionamento está na diversidade de perfis que os candidatos do gênero masculino assumem. Em outras palavras, os homens não estão associados a nenhum perfil específico, pois, nos dados aqui estudados, eles existem com as mais variadas características. Ao contrário disso, é possível observar, em todos os modelos, a modalidade correspondente ao sexo feminino na seguinte posição: ao longo do primeiro eixo, na parte associada ao não sucesso eleitoral; ao longo do segundo eixo, na parte associada a estratos sócio-profissionais intensivos em capital cultural. Essa posição permite concluir que as mulheres estão entre o grupo de candidatos de desempenho eleitoral mal sucedida e, ainda, entre o grupo de candidatos de alta escolaridade e com ocupações como profissões liberais e intelectuais, administração pública ou 
professores. De fato, dentre as candidaturas de mulheres nas três eleições estudadas, $16,9 \%$ eram de candidatas professoras. Número bem superior às candidaturas masculinas, dentre as quais apenas $6,5 \%$ eram de professores. Além disso, as mulheres apresentam uma maior proporção de alta escolaridade. Dentre as candidaturas femininas, $57,1 \%$ eram mulheres que possuíam ensino superior, contra $50 \%$ dos homens.

\section{Exemplos de Posições}

Até aqui, foi explorada a maneira segundo a qual as características dos candidatos se distribuem ao longo de diferentes dimensões, os eixos fatoriais produzidos na ACM, relevantes para a compreensão de suas distinções. Nessa seção, deixamos um pouco de lado o exame das modalidades das variáveis para nos voltarmos aos indivíduos, os quais são apresentados no plano do primeiro e do segundo eixos. O intuito aqui é demonstrar como diferentes posições nesse espaço determinam diferentes perfis dos candidatos.

Gráfico 5 - Indivíduos no plano com o primeiro e o segundo eixos fatoriais. Todas as candidaturas, 1998-2006.

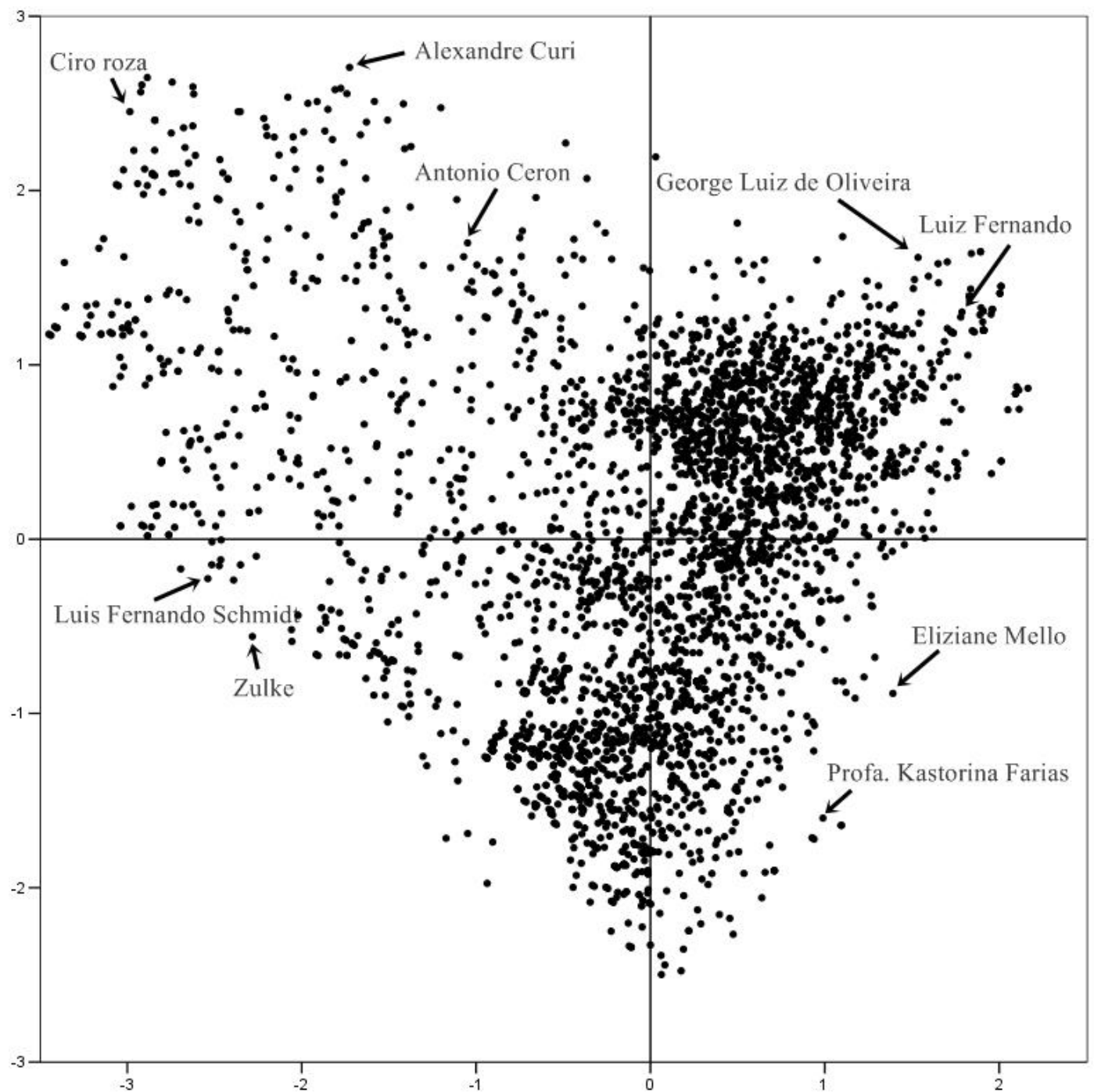


O Gráfico 5 traz os candidatos distribuídos no plano do primeiro e do segundo eixos fatoriais. Selecionamos alguns candidatos que servem como exemplos de diferentes posições correspondentes a diferentes perfis. No primeiro quadrante (esquerda-superior), localizam-se os candidatos com um perfil caracterizado por um maior grau de sucesso eleitoral e pelo pertencimento a estratos sócio-ocupacionais não intensivos em capital cultural ou, entendido de outro modo, a estratos sócio-ocupacionais detentores de poderes econômicos e políticos (ou submetidos a esses poderes). As posições nesse espaço estão normalmente associadas à filiação em grandes partidos. Ciro Roza, por exemplo, está indicado no Gráfico 5 no ponto representando sua candidatura a deputado estadual em Santa Catarina na eleição de 1998. Filiado ao PFL, ele já havia sido eleito em 1994 para esse mesmo cargo e se elegeu novamente em 1998. Ele se declarou como político profissional ao Tribunal Eleitoral tinha 52 anos na época da candidatura, era casado e possuía o segundo grau completo. Outro exemplo, também indicado no gráfico, é Alexandre Curi. $\mathrm{O}$ ponto indicado representa sua candidatura a deputado estadual no Paraná em 2006. Alexandre Curi é filiado ao PMDB, já havia sido eleito para esse cargo na eleição anterior e se reelegeu em 2006. Ele também se declarou político profissional, tinha 27 anos na época da candidatura, era solteiro e possuía o ensino médio completo. Um último exemplo para esse perfil é Antônio Ceron. O ponto indicado corresponde a sua candidatura a deputado estadual em Santa Catarina na eleição de 2002. Ceron se elegeu pela primeira vez a esse cargo em 2002 e era filiado ao PFL. Ele se declarou empresário, tinha 57 anos na época da candidatura, era casado e possuía o ensino médio completo. Esses exemplos permitem ilustrar concretamente esse polo ocupado por pessoas com o seguinte perfil: sucesso eleitoral e, ao mesmo tempo, pertencentes a estratos sócio-ocupacionais detentores de poderes econômicos e políticos.

$\mathrm{O}$ segundo quadrante (direita-superior) abrange os candidatos com do mesmo estrato sócio-ocupacional ilustrado anteriormente; entretanto, com uma correspondência maior às categorias de trabalhador industrial, lavrador e empregado não manual em serviços. Além disso, os indivíduos desse quadrante estão associados ao não sucesso eleitoral e à filiação a pequenos partidos. Para ilustrar esse perfil, mencionaremos dois exemplos. O primeiro é George Luiz de Oliveira. O ponto indicado no Gráfico 5, representa sua candidatura a deputado estadual no Paraná em 1998. Filiado ao PMN, ele não se elegeu nessa eleição. Ele se declarou empresário, tinha 27 anos na época da candidatura, era solteiro e possuía o segundo grau incompleto. O segundo é Luis Fernando, candidato em 1998 pelo PSTU no Paraná. Ele se declarou estudante, tinha 22 anos em 1998, era solteiro e possuía o segundo grau completo.

$\mathrm{O}$ terceiro quadrante (direita-inferior) corresponde a um perfil com os seguintes aspectos. Em primeiro lugar, a performance eleitoral mal sucedida. Em segundo lugar, pertencimento a estratos sócio-ocupacionais intensivos em capital cultural. Um primeiro exemplo é a Professora Kastorina Farias, candidata a deputado estadual no Paraná pelo PMN em 2006. Como sugere seu nome de urna, ela é professora, tinha 50 anos na época da candidatura, era solteira, possuía curso superior completo e não logrou se eleger. Um segundo exemplo é Eliziane Mello. Ela foi candidata pelo PSB no Rio Grande do Sul em 2006. Não eleita, Mello é servidora pública municipal, tinha 22 anos na época da candidatura, era solteira e possuía curso superior completo.

$\mathrm{O}$ quarto quadrante (esquerda-inferior) abriga as posições associadas ao desempenho 
eleitoral bem sucedido e ao pertencimento a estratos profissionais intensivos em capital cultural. A essas posições, normalmente também se relaciona a filiação a grandes partidos. Um primeiro exemplo desse perfil é Ronaldo Miro Zulke, candidato no Rio Grande do Sul na eleição de 2002. Filiado ao PT, Zulke se reelegeu nesse ano para o cargo de deputado estadual. Ele se declarou professor, tinha 48 anos na época da eleição, era casado e possuía superior completo. Um segundo exemplo é Luis Fernando Schmidt, candidato também no Rio Grande do Sul em 2002. O caso de Schmidt é bastante semelhante ao de Zulke, pois ele também filiado ao PT e também se reelegeu nesse ano. Schmidt se declarou odontólogo, tinha 42 anos na época da eleição, era casado e possuía superior completo.

\section{Considerações Finais}

Ao investigar os candidatos a deputado estadual nos três Estados do sul no período 1998-2006, realizamos um exercício de sociologia política com dois objetivos. Em primeiro lugar, mostramos quais são os diferentes perfis para o conjunto dos candidatos. Os candidatos se distribuem em duas dimensões relevantes. A primeira divide candidatos que possuem sucesso eleitoral daqueles que não possuem. O segundo separa candidatos pertencentes a estratos sócioocupacionais cujas atividades envolvem uso mais intensivo relativamente de recursos culturais de estratos cujas atividades não são relativamente tão intensivas nesse tipo de recursos. Esse último grupo também pode ser entendido como um grupo de candidatos ligados a poderes econômicos e políticos ou a candidatos submetidos a esses poderes. Cruzando-se essas duas dimensões, representadas pelos eixos da ACM, é possível observar as diferentes posições dos candidatos, as quais se constituem como diferentes perfis sócio-políticos.

$\mathrm{O}$ segundo objetivo foi introduzir a Análise de Correspondências Múltiplas enquanto técnica capaz de processar a associação entre diversas variáveis simultaneamente. Com isso, é possível ir além de técnicas mais simples, como tabelas cruzadas, e se chegar a resultados que envolvam a relação entre todo o conjunto de variáveis. Com a ACM, foi possível observar que, apesar de utilizarmos 9 variáveis em cada modelo (10 no modelo com os dados de todos os anos), as diferenças entre os indivíduos pode ser reduzida a duas dimensões relevantes, cujos significados substantivos vão além do que diz uma ou outra variável individual.

1 A utilidade da ACM e de suas variantes pode ser atestada em diversos exemplos. Na investigação de diferentes padrões de democracia, em Lijphart (1999) e de diferentes variedades de capitalismo, como em Amable (2003). No estudo do espaço dos eleitores franceses, em Perrineau (2000). Bastante conhecida na sociologia francesa, a utilização da ACM tem seu exemplo clássico em Bourdieu (1979), que explora o espaço dos diferentes estilos de vida (ROUANET et al., 2000); Lebaron (2008) que apresenta um estudo dos presidente de Bancos Centrais como espaço social. Para um exemplo de estudo utilizando essa técnica no Brasil, ver, por exemplo, Hey (2008).

2 A proporções de variância dos dados explicadas com a retenção desses dois eixos para a análise são as seguintes: $\mathrm{ACM}_{\text {total }}=39 \%, \mathrm{ACM}^{1998}=$ $44 \%, \mathrm{ACM}^{2002}=43 \%, \mathrm{ACM}^{2006}=44 \%$. Os resultados para o terceiro eixo fatorial não são analisados, pois podem ser interpretados como um refinamento dos resultados para o segundo eixo. A razão para essa interpretação está nas variáveis que mais contribuem para a formação do terceiro eixo nas ACMs, as quais repetem as variáveis do segundo eixo, com alguns acréscimos ou variações.

3 Partido Progressista Brasileiro (PPB) altera sua nomenclatura em 2005 para Partido Progressista (PP). Por essa razão, o PPB desaparece da análise na 
eleição de 2006, sendo substituído pelo PP.

\section{Referências}

AMABLE, Bruno. The Diversity of Modern Capitalism. New York: Oxford University Press, 2003.

ARAÚJO, Clara. O. Partidos Políticos e Gênero: mediações nas rotas de ingresso das mulheres na política. Revista de Sociologia e Política, v. 24, n. 24, p. 193 - 216, 2005.

AVELAR, Lúcia. Mulheres na elite política brasileira. 2. ed. São Paulo: Fundação Konrad Adenauer/Ed. Unesp, 2001.

BENZÉCRI, Jean-Paul. Correspondence Analysis Handbook. New York: Marcel Dekker, 1992.

BOURDIEU, Pierre. La Distiction. Paris: Éditions de Minuit, 1979.

ESCOFIER, Brigitte; PAGÈS, Jérôme. Analisis Factoriales Simples y Multiples. Bilbao: Ed. Universidad del Pais Vasco, 1992.

FIGUEIREDO, Argelina; LIMONGI, Fernando. Executivo e Legislativo na Nova Ordem Constitucional. Rio de Janeiro: Ed. FGV, 1999.

HEY, Ana Paula. Esboço de uma sociologia do campo acadêmico: A educação superior no Brasil. São Carlos/SP: Ed. UFSCar, 2008.

LEBARON, Frédéric. L'enquête quantitative en sciences sociales. Paris: Dunod, 2006.

LEBARON, Frédéric. Central bankers in the contemporary global field of power: a 'social space' approach. Sociological Review, v. 56, p. 121 - 144, 2008.

MARENCO DOS SANTOS, André. Nas fronteiras do campo político: raposas e outsiders no Congresso Nacional. Revista Brasileira de Ciências Sociais, v. 33, p. 87 101, 1997.

KINZO, Maria D'Alva. Radiografia do Quadro Partidário Brasileiro. São Paulo: Konrad-Adenauer Stiftung, 1993.

LEONI, Eduardo. Ideologia, Democracia e Comportamento Parlamentar: A Câmara dos Deputados (1991-1998). Dados, v. 45, n. 3, p. $361-386,2002$.

LIJPHART, Arend. Patterns of Democracy. New Haven: Yale University Press, 1999.

MAINWARRING, Scott; MENEGUELLO, Rachel; POWER, Timothy Joseph. Partidos Conservadores no Brasil Contemporâneo. São Paulo, Paz e Terra, 2000.

MIGUEL, Luiz Felipe. Capital político e carreira eleitoral: algumas variáveis na eleição para o congresso brasileiro. Revista de Sociologia e Política, v. 20, p. 115 - 134, 2003.

MIGUEL, Luis Felipe; BIROLI, Flávia. Mídia e representação política feminina: hipóteses de pesquisa. Opinião Pública, v. 15, p. $55-81,2009$.

PERISSINOTO, Renato; BRAUNERT, Mariana. A direita, a esquerda e a democracia: os valores políticos dos parlamentares paranaenses (1995-2002). Opinião Pública, v. 12, n. 1, p. 114 - 135, 2006.

PERISSINOTO, Renato; COSTA, Luiz Domingos; TRIBESS, Camila. Origem social dos parlamentares paranaenses (1995-2006). Sociologias, n. 22, p. 280 - 313, 2009.

PERRINEAU, Pascal; CHICHE, Jean; LE ROUX, Brigitte; ROUANET, Henry. 
L'espace politique des électeurs français à la fin des années 1990. Revue française de science politique, v. 50 , n. 3 , p. $463-488$, 2000 .

ROUANET, Henry; ACKERMANN, Wemer; LE ROUX, Brigitte. The geometric analysis of questionnaires: the lesson of Bourdieu's La Distinction. Bulletin de Méthodologie sociologique, n. 65 , p. 5 - 18, 2000.

ROUANET, Henry. The geometric analysis of structured individuals $\mathrm{x}$ variables tables. in: GREENACRE, Michael; BLASIUS, Jorg. Multiple Correspondence Analysis and Related Methods. Boca-Raton: Chapman \& Hall, 2005.

RODRIGUES, Leôncio Martins. Partidos, Ideologia e Composição Social : um estudo das bancadas partidárias na Câmara dos Deputados. São Paulo: Edusp, 2002.

ZUCCO, Cesar. Estimating Ideology of Brazilian Legislative Parties: 1990-2005. Latin American Research Review, v. 44, n. 1, p. 218 - 246, 2009. 
Eleições e Perfis: análise das assembleias legislativas da

região Sul do Brasil (1998-2006)

Apêndice Tabela 2 - Sumário dos modelos.

Total

\begin{tabular}{|crrr|}
\hline \multirow{2}{*}{ Eixo } & \multirow{2}{*}{ Afa de Cronbach } & \multicolumn{3}{c|}{ Variância explicada por } \\
\cline { 2 - 4 } & & Total (Autovalor) & \% da variância \\
\hline 1 & 0,6 & 2,18 & 22 \\
\hline 2 & 0,45 & 1,68 & 17 \\
\hline 3 & 0,37 & 1,51 & 15 \\
\hline 4 & 0,28 & 1,33 & 13 \\
\hline Total & & 13,81 & \\
\hline Média & 0,31 & 1,38 & 14 \\
\hline
\end{tabular}

1998

\begin{tabular}{|crrr|}
\hline \multirow{2}{*}{ Eixo } & Alfa de Cronbach & \multicolumn{3}{c|}{ Variância explicada por } \\
\cline { 3 - 4 } & & Total (Autovalor) & \% da variância \\
\hline 1 & 0,63 & 2,26 & 25 \\
\hline 2 & 0,46 & 1,68 & 19 \\
\hline 3 & 0,41 & 1,58 & 18 \\
\hline 4 & 0,28 & 1,32 & 15 \\
\hline Total & & 13,95 & \\
\hline Média & 0,32 & 1,4 & 16 \\
\hline
\end{tabular}

2002

\begin{tabular}{|c|c|c|c|}
\hline \multirow{2}{*}{ Eixo } & \multirow{2}{*}{ Alfa de Cronbach } & \multicolumn{2}{|c|}{ Variância explicada por } \\
\hline & & Total (Autovalor) & \% da variância \\
\hline 1 & 0,6 & 2,15 & 24 \\
\hline 2 & 0,47 & 1,73 & 19 \\
\hline 3 & 0,41 & 1,58 & 18 \\
\hline 4 & 0,3 & 1,36 & 15 \\
\hline Total & & 13,92 & \\
\hline Média & 0,32 & 1,39 & 16 \\
\hline
\end{tabular}

2006

\begin{tabular}{|crrr|}
\hline \multirow{2}{*}{ Eixo } & \multirow{2}{*}{ Alfa de Cronbach } & \multicolumn{3}{c|}{ Variância explicada por } \\
\cline { 3 - 4 } & & Total (Autovalor) & \% da variância \\
\hline 1 & 0,63 & 2,25 & 25 \\
\hline 2 & 0,45 & 1,68 & 19 \\
\hline 3 & 0,37 & 1,48 & 17 \\
\hline 4 & 0,32 & 1,4 & 16 \\
\hline Total & & 13,86 & \\
\hline Média & 0,31 & 1,39 & 15 \\
\hline
\end{tabular}

Roberta Carnelos Resende e Rodrigo Cantu de Souza 


\begin{tabular}{|cccc|}
\multirow{2}{*}{ Variáveis } & \multicolumn{3}{c|}{ Dimensão } \\
\cline { 2 - 4 } & $\mathbf{1}$ & 2 & 3 \\
\hline Ano da eleiçāo & 0,025 & 0,000 & 0,102 \\
\hline Estado & 0,003 & 0,009 & 0,023 \\
\hline Partido & $\mathbf{0 , 2 8 7}$ & 0,111 & $\mathbf{0 , 2 5 0}$ \\
\hline Situaçāo & $\mathbf{0 , 4 8 1}$ & 0,105 & 0,054 \\
\hline Gênero & 0,021 & 0,060 & 0,035 \\
\hline Em Mandato & $\mathbf{0 , 5 0 7}$ & 0,129 & 0,041 \\
\hline Ocupaçāo & $\mathbf{0 , 4 3 5}$ & $\mathbf{0 , 6 7 2}$ & $\mathbf{0 , 2 8 3}$ \\
\hline Idade & 0,122 & 0,034 & $\mathbf{0 , 3 0 0}$ \\
\hline Estado Civil & 0,117 & 0,024 & $\mathbf{0 , 2 9 8}$ \\
\hline Escolaridade & 0,179 & $\mathbf{0 , 5 3 3}$ & 0,123 \\
\hline total & 2,178 & $\mathbf{1 , 6 7 6}$ & $\mathbf{1 , 5 0 8}$ \\
\hline
\end{tabular}

\begin{tabular}{|cccc|}
\hline \multirow{2}{*}{ Variáveis } & \multicolumn{3}{c|}{ Dimensão } \\
\cline { 2 - 4 } & $\mathbf{1}$ & 2 & 3 \\
\hline Estado & 0,002 & 0,007 & 0,134 \\
\hline Situação & $\mathbf{0 , 3 3 3}$ & $\mathbf{0 , 1 8 9}$ & 0,072 \\
\hline Gênero & 0,021 & 0,096 & 0,000 \\
\hline Em Mandato & $\mathbf{0 , 3 9 9}$ & $\mathbf{0 , 1 9 2}$ & 0,018 \\
\hline Ocupação & $\mathbf{0 , 4 2 4}$ & $\mathbf{0 , 5 7 6}$ & $\mathbf{0 , 2 3 0}$ \\
\hline Idade & 0,169 & 0,024 & $\mathbf{0 , 3 8 1}$ \\
\hline Estado Civil & 0,110 & 0,042 & $\mathbf{0 , 3 0 3}$ \\
\hline Escolaridade & $\mathbf{0 , 3 4 4}$ & $\mathbf{0 , 3 9 5}$ & $\mathbf{0 , 1 7 3}$ \\
\hline Partidos 2002 & $\mathbf{0 , 3 4 4}$ & $\mathbf{0 , 2 0 7}$ & $\mathbf{0 , 2 6 5}$ \\
\hline total & 2,146 & $\mathbf{1 , 7 2 7}$ & $\mathbf{1 , 5 7 5}$ \\
\hline
\end{tabular}

\begin{tabular}{|cccc|}
\hline \multirow{2}{*}{ Variáveis } & \multicolumn{3}{c|}{ Dimensão } \\
\cline { 2 - 4 } & 1 & 2 & 3 \\
\hline Estado & 0,003 & 0,030 & 0,014 \\
\hline Situação & $\mathbf{0 , 5 5 4}$ & 0,056 & 0,042 \\
\hline Gênero & 0,018 & 0,071 & 0,079 \\
\hline Em Mandato & $\mathbf{0 , 6 0 4}$ & 0,072 & 0,029 \\
\hline Ocupação & $\mathbf{0 , 4 5 4}$ & $\mathbf{0 , 7 0 1}$ & $\mathbf{0 , 3 5 3}$ \\
\hline Idade & 0,126 & 0,039 & $\mathbf{0 , 3 7 5}$ \\
\hline Estado Civil & 0,098 & 0,029 & $\mathbf{0 , 3 1 4}$ \\
\hline Escolaridade & 0,111 & $\mathbf{0 , 5 9 8}$ & 0,075 \\
\hline Partidos 1998 & $\mathbf{0 , 2 9 0}$ & 0,084 & $\mathbf{0 , 2 9 5}$ \\
\hline total & 2,259 & 1,683 & 1,578 \\
\hline
\end{tabular}

\begin{tabular}{|cccc|}
\hline \multirow{2}{*}{ Variáveis } & \multicolumn{3}{c|}{ Dimensão } \\
\cline { 2 - 4 } & $\mathbf{1}$ & 2 & 3 \\
\hline Estado & 0,020 & 0,007 & 0,005 \\
\hline Partidos 2006 & $\mathbf{0 , 2 8 4}$ & 0,083 & $\mathbf{0 , 1 4 9}$ \\
\hline Situação & $\mathbf{0 , 5 2 3}$ & 0,065 & 0,013 \\
\hline Gênero & 0,008 & 0,030 & 0,068 \\
\hline Em Mandato & $\mathbf{0 , 5 5 3}$ & 0,131 & 0,012 \\
\hline Ocupação & $\mathbf{0 , 5 1 9}$ & $\mathbf{0 , 6 7 3}$ & $\mathbf{0 , 2 4 2}$ \\
\hline Idade & 0,117 & 0,086 & $\mathbf{0 , 4 3 0}$ \\
\hline Estado Civil & 0,087 & 0,041 & 0,448 \\
\hline Escolaridade & 0,138 & $\mathbf{0 , 5 5 8}$ & 0,115 \\
\hline total & 2,249 & 1,675 & 1,483 \\
\hline
\end{tabular}

